\title{
Efektivitas Media Pembelajaran Anatomi Kadaver Dibandingkan Video Terhadap Pemahaman Neuroanatomi pada Mahasiswa Kedokteran
}

\author{
Prasetya Utami $^{1}$, Yunia Hastami ${ }^{2}$, Siti Munawaroh ${ }^{2}$, Nanang Wiyono ${ }^{2}$ \\ 1. Program Studi Kedokteran Universitas Sebelas Maret \\ 2. Departemen Anatomi Fakultas Kedokteran Universitas Sebelas Maret
}

Korespondensi : prasetyautami09@gmail.com

\begin{abstract}
ABSTRAK
Pendahuluan : Neuroanatomi merupakan ilmu penting bagi kedokteran, namun masih ditemukan mahasiswa kedokteran yang merasa kesulitan memahami pembelajaran neuroanatomi. Salah satu faktor yang berperan penting adalah media pembelajaran anatomi. Kadaver merupakan media pembelajaran anatomi tradisional yang masih digunakan hingga saat ini dengan berbagai kekurangan dan kelebihan yang dimilikinya. Sedangkan media video merupakan media pembelajaran anatomi yang diniliai lebih praktis dan sesuai dengan perkembangan zaman, sehingga di nilai bisa sebagai media alternatif selain kadaver. Penelitian ini bertujuan untuk mengetahui efektivitas media pembelajaran anatomi menggunakan kadaver dibandingkan video terhadap pemahaman neuroanatomi mahasiswa kedokteran.

Metode : Jenis penelitian ini ialah Quasi Experimental Research dengan Pretest Posttest Control Group Design. Populasi dalam penelitian ini adalah mahasiswa program studi kedokteran UNS tahun 2019. Sampel dalam penelitian ini sebanyak 42 oranag. Data kemudian diolah dengan uji Paired Sample T-Test dan Independent T-test menggunakan program SPSS 22.

Hasil : Hasil Paired Sample T-Test kelompok kadaver dan video menunjukan nilai Sig. (2-tailed) $<0,05$ yaitu 0,000. Sehingga media kadaver maupun video dinilai efektif terhadap pemahaman neuroanatomi mahasiswa. Hasil uji Independent T-test untuk mengetahui perbedaan antara efektivitas media pembelajaran anatomi menggunakan kadaver dibandingkan video terhadap pemahaman neuroanatomi mahasiswa kedokteran memperlihatkan nilai $\mathrm{p}=0,730$, sehingga menunjukkan hasil yang tidak signifikan karena $\mathrm{p} \geq 0,05$ pada taraf signifikan $5 \%$.

Kesimpulan : Media pembelajaran anatomi kadaver maupun video terbukti efektif meningkatkan pemahaman neuroanatomi pada mahasiswa kedokteran. Selain itu, media pembelajaran anatomi kadaver dibandingkan video memiliki efektivitas yang sama terhadap pemahaman neuroanatomi pada mahasiswa kedokteran
\end{abstract}

Kata kunci : Kadaver; Video Anatomi; Pemahaman Neuroanatomi

\section{ABSTRACT}

Introduction: Neuroanatomy is an important science for medicine, but there are still medical students difficult to understand neuroanatomy. One factor that important is the anatomy learning media. Cadaver is a traditional anatomy learning media that is still used today with its various superiority and shortcomings. While video media is an anatomy learning media that is judged to be more practical and in accordance with the times, so it can be assessed as a alternative media other than cadaver. This study aims to determine the effectiveness of the anatomy learning media using cadavers compared to videos on neuroanatomy understanding of medical students.

Method: This type of research is Quasi Experimental Research with Pretest Posttest Control Group Design. The population in this study were students of the 2019 UNS medical study program. The samples in this study were 42 people. The data is then processed by Paired Sample T-Test and Independent T-test using SPSS 22 program.

Results: Paired Sample T-Test of cadaveric group and video shows the Sig. (2-tailed) $<0.05$ which is 0,000. So that cadaveric and video media are considered effective against students' neuroanatomy understanding. Independent T-test results to find out the difference between the effectiveness of anatomical learning media using cadavers versus video on neuroanatomy understanding of medical students showed a value of $p=0.730$, thus showing insignificant results because $p \geq 0.05$ at the significant level of $5 \%$.

Correspondence: Prasetya Utami, Fakultas Kedokteran Universitas Sebelas Maret, prasetyautami09@gmail.com 
Conclusion: Cadaveric anatomy and video learning media have proven that effective in increasing neuroanatomy understanding in medical students. In addition, cadaveric anatomy learning media compared to video have the same effectiveness on neuroanatomy understanding in medical students.

Keywords: Cadaver, Anatomy Video, Neuoranatomy

\section{PENDAHULUAN}

Ilmu anatomi merupakan ilmu yang penting untuk digunakan dalampraktik kedokteran. Namun, masih ditemukan mahasiswa kedokteran yang merasa kesulitan memahami pembelajaran anatomi ${ }^{1}$.Ada beberapa faktor yang menyebabkan mahasiswa sulit menguasai materi anatomi antara lain; pemilihan media pembelajaran kurang tepat, materi yang banyak, minimnya durasi pembelajaran, dan metode pembelajaran yang kurang tepat. Dalam hal ini media pembelajaran merupakan salah satu faktor penting dalam proses pembelajaran, karena penggunaan media pembelajaran yang tepat bisa membuat penyampaian materi lebih mudah dipahami dan menarik.

Media pembelajaran anatomi selalu berkembang sesuai perkembangan jaman. Diseksi kadaver merupakan media pembelajaran utama anatomi sejak 400 tahun yang lalu ${ }^{2}$. Kemudian bekembang media proseksi kadaver yang dinilai lebih efisien waktu, media plastinasi, dan media anatomy living yang sangat berguna untuk kepentingan pemeriksaan dan diagnostik klinik. Perkembangan teknologi yang pesat turut memberi andil pada perkembangan media pembelajaran anatomi. Media pembelajaran medical imaging dan media pembelajaran berbasis komputer seperti video berisi diseksi kadaver mulai eksis pada tahun 1990an, dan semakin berkembang pesat hingga kini.

Beberapa penelitian sebelumnya telah membandingkan efektifivitas media kadaver dibandingkan media video, namun beberapa hasil penelitian tersebut memiliki perbedaan hasil karena beberapa faktor. Kadaver merupakan media pembelajaran anatomi tradisional yang masih digunakan hingga saat ini dengan berbagai kekurangan dan kelebihan yang dimiliki. Sedangkan media video anatomi diniliai lebih praktis dan sesuai dengan perkembangan zaman, sehingga di nilai bisa sebagai media alternatif selain kadaver. Selain itu, terdapat masalah pembelajaran anatomi di Kedokteran UNS yaitu hanya kurang dari 30\% mahasiswa yang lulus ujian responsi blok neurologi sejak 2014-2017. Perubahan pada media pembelajaran diharapkan bisa memperbaiki pemahaman mahasiswa mengenai materi neuroanatomi. Hal ini sejalan dengan penelitian sebelumnya media pembelajaran video anatomi, dinilai efektif, praktis, dan menarik bagi mahasiswa kedokteran sebagai media pengajaran ${ }^{1}$.

Dari latar belakang di atas peneliti tertarik untuk mengangkat fakta permasalahan dengan judul, "Efektivitas Media Pembelajaran Anatomi Kadaver Dibandingkan Video Terhadap Pemahaman Neuroanatomi pada Mahasiswa Kedokteran".

\section{SUBJEK DAN METODE}

Penelitian ini adalah Quasi Experimental Research atau penelitian eksperimen semu. Desain yang digunakan dalam penelitian ini adalah Pretest Posttest Control Group Design.

Subjek penelitian ini adalah mahasiwa semester pertama di program studi Kedokteran UNS dengan kriteria inklusi Mahasiswa Program Studi Kedokteran UNS semester pertama dan belum mendapatkan materi neuroanatomi diperkuliahan. Sedangkan kriteria ekslusinya yaitu Sampel yang berhenti atau tidak mengikuti penelitian dari awal hingga akhir. Sampel yang tidak mengembalikan soal yang diberi lengkap dari peneliti. Teknik pengambilan sampel yang digunakan adalah teknik cluster random sampling yang dilakukan pada dua puluh kelompok 
SGD yang ada di program studi kedokteran UNS angkatan 2019. Sampel dipilih empat kelompok SGD secara acak, kemudian dari sampel tersebut dibagi secara acak kembali menjadi dua kelompok. Yaitu sebagai kelompok kadaver dan kelompok video. Penelitian dilakukan mulai bulan Desember 2019 dengan memilih sampel secara cluster random sampling sesuai dengan kriteria inklusi dan ekslusi yang telah ditetapkan.

Variabel terikat dalam penelitian ini yaitu pemahaman materi neuroanatomi. Sedangkan variabel bebasnya terdapat 2, yaitu kelompok kadaver sebagai kelompok pertama dan kelompok video anatomi sebagai kelompok kedua.

Data yang diperoleh kemudian dianalisis dengan uji statistik T-test Independent menggunakan SPSS 22. Penelitian ini sudah mendapat Ethical Clearance Penelitian Fakultas Kedokteran Universitas Sebelas Maret

\section{HASIL}

\section{Deskripsi Data}

Subjek penelitian yang dilibatkan dalam penelitian ini adalah Mahasiswa Tahun pertama Program Studi Kedokteran Fakultas Kedokteran UNS. Berdasarkan kriteria inklusi dan eksklusi serta random cluster sampling, didapatkan kelompok SGD A1 dan A8 sebagai kelompok video, dan kelompok SGD A4 dan B3 sebagai kelompok kadaver. Sehingga jumlah keseluruhan mahasiwa yang mengikuti kegiatan penelitian yaitu 42 mahasiswa. Berikut ini adalah deksripsi subjek penelitian kelompok kadvaer dan kelompok video.

Tabel 1. Deskripsi Subjek Penelitian

\begin{tabular}{cccc}
\hline \multirow{2}{*}{ Kelompok } & \multicolumn{2}{c}{ Jenis Kelamin } & \multirow{2}{*}{ Jumlah } \\
\cline { 2 - 3 } & Laki-laki & Perempuan & \\
\hline Kadaver & 7 & 14 & 21 \\
Video & 8 & 13 & 21 \\
\hline \multicolumn{3}{c}{ Total Subjek Penelitian } & 42 \\
\hline
\end{tabular}

Tabel 2. Daftar rekapitulasi rerata nilai pada kelompok kadaver dan kelompok video Rerata Nilai

\begin{tabular}{cccc}
\hline Kelompok & Pretes & Postes & Kenaikan nilai \\
\hline Kadaver & 30 & 48.21 & 10.71 \\
Video & 30.59 & 58.09 & 15.95 \\
\hline
\end{tabular}

\section{Pengujian Hipotesis}

Analisis data yang digunakan dalam penelitian ini adalah Uji mengetahui efektivitas media pembelajaran menggunakan Uji Paired Sample T-Test dan Uji beda dengan menggunakan Independent T-Test.

Tabel 3. Hasil analisis uji paired sample t-test

\begin{tabular}{ccc}
\hline Data & Sig (2-tailed) & Kesimpulan \\
\hline Kelompok Kadaver & .000 & Efektif terhadap peningkatan pemahaman neuroanatomi \\
Kelompok Video & .000 & Efektif terhadap peningkatan pemahaman neuroanatomi \\
\hline
\end{tabular}


Berdasarkan tabel dapat diketahui bahwa media kadaver maupun video efektif untuk meningkatkan pemahaman neuroanatomi karena terdapat perbedaan signifikan antara rerata nilai pretest dengan posttest pada kelompok perlakuan.

Tabel 4. Hasil uji independent t-test

\begin{tabular}{ccc}
\hline Data & Sig (2-tailed) & Kesimpulan \\
\hline $\begin{array}{c}\text { Kelompok Kadaver dan } \\
\text { Video }\end{array}$ & .730 & $\begin{array}{c}\text { Efektif terhadap peningkatan pemahaman } \\
\text { neuroanatomi }\end{array}$ \\
\hline
\end{tabular}

Berdasarkan hasil uji independent $t$ test pada kenaikan nilai pemahaman neuranatomi, dapat diketahui bahwa taraf signifikansinya (2-tailed) adalah 0,730 yang menunjukkan bahwa $0,730 \geq 0,05$. Maka dari itu tidak terdapat perbedaan (sama) signifikan antara hasil pemahaman neuroanatomi pada kelompok kadaver dan kelompok video.

\section{PEMBAHASAN}

Hasil dari penelitian ini menunjukkan bahwa perbandingan hasil dari kenaikan nilai pemahaman neuroanatomi memiliki taraf signifikansi (2-tailed) adalah 0,730 yang berarti 0,730 $\geq 0,05$. Hal ini menunjukkan bahwa media pembelajaran anatomi kadaver dibandingkan video memiliki efektivitas yang sama terhadap pemahaman neuroanatomi pada mahasiswa kedokteran. Hasil penelitian ini sesuai dengan penelitian sebelumnya yang telah dilakukan Berrios Barillas, R. (2019) pada 35 mahasiswa terapi okupasi menunjukkan bahwa pemahaman anatomi mahasiswa yang menggunakan media anatomy software (video) memberikan hasil lebih tinggi namun tidak signifikan $(\mathrm{p}=0.364)$ dibandingkan menggunakan media tradisional seperti kadaver ${ }^{3}$. Hal ini menunjukkan hasil serupa dengan penelitian yang dilakukan oleh peneliti yaitu tidak ada perbedaan signifikan antara media pembelajaran kadaver dibanding video terhadap pemahaman anatomi subjek penelitian.

Hasil penelitian ini tetap bisa digunakan sebagai referensi bahwa terdapat alternatif lain media pembelajaran anatomi yang sama efektifnya dengan kadaver yaitu media video anatomi. Dibanding kadaver yang memiliki kelemahan berupa biaya mahal, paparan formalin, etika kedokteran, tidak responsif pemeriksaan, dan perubahan pada struktur, tekstur, dan warna yang tidak seperti pada manusia hidup ${ }^{4,5}$. Media video anatomi dinilai memiliki keunggulan yaitu memberikan kesempatan mahasiswa untuk belajar mandiri sehingga lebih efisien waktu dan fleksibel, dan lebih mudah dipahami siswa ${ }^{6}$. Oleh karena itu media video ini bisa digunakan untuk pembelajaran anatomi tanpa harus menunggu jadwal praktikum yang jumlahnya terbatas pada setiap topiknya.

Penelitian Pani et al. pada 40 mahasiswa S1 di Departmentof Psicology and Brain Science di Universitas Lousville melaporkan bahwa mempelajari neuroanatomi dinilai lebih menarik dan mudah dipahami jika menggunakan video anatomi ${ }^{7}$. Selain itu, penelitian yang dilakukan oleh Tam et al. menyebutkan bahwa penggunanaan bersamaan antara media video dan media kadaver ini dapat meningkatkan pemahaman anatomi yang lebih maksimal ${ }^{8}$. Hal ini juga didukung oleh hasil penelitian Losco et al. yang menyebutkan bahwa kombinasi antara media video 2-dimensi maupun 3-dimensi dengan media kadaver dinilai terbukti lebih baik untuk meningkatkan nilai mahasiswa ${ }^{9,10,11}$. Oleh karena itu, media video anatomi bisa digunakan sebagai media alternatif dan bisa dikombinasikan dengan media kadaver untuk mencapai pemahaman mahasiswa lebih baik. 
Terdapat keterbatasan dalam peneliti melaksanakan eksperimen ini. Salah satu aspek yang dapat mengurangi akurasi hasil penelitian adalah faktor yang tidak dapat dikendalikan oleh peneliti, diantaranya yaitu faktor dari subjek penelitian, faktor dari susunan video, faktor pengajar, dan faktor topik materi yang digunakan dalam penelitian. Faktor dari subjek penelitian memberi pengaruh besar terhadap hasil penelitian, antara lain: perbedaan tingkat keseriusan subjek penelitian dalam mengikuti kegiatan penelitian dan faktor internal dari subjek penelitian yang terdiri dari kecerdasan intelektual, minat, motivasi, dan gaya belajar. Selain itu, dari observasi yang dilakukan peneliti ditemukan bahwa banyak subjek yang tidak fokus dengan materi karena waktu pengambilan data kelompok dilakukan tepat setelah kelompok tersebut melaksanakan ujian OSCE. Faktor lainnya adalah susunan materi pada video yang merupakan gabungan dari beberapa video dari jenis media anatomi yang berbeda-beda (kadaver, manekin, animasi) menyebabkan subjek penelitian bingung, dan jumlah soal sebanyak 40 butir membuat subjek kesulitan memahami seluruh materi.

\section{KESIMPULAN}

Berdasarkan hasil penelitian dapat disimpulkan bahwa media pembelajaran anatomi kadaver maupun video terbukti efektif meningkatkan pemahaman neuroanatomi pada mahasiswa kedokteran. Selain itu, media pembelajaran anatomi kadaver dibandingkan video memiliki efektivitas yang sama terhadap pemahaman neuroanatomi pada mahasiswa tahun pertama program studi kedokteran FK UNS. Sehingga media pembelajaran video anatomi bisa menjadi alternatif mempelajarai anatomi secara mandiri bagi mahasiswa dan bisa dijadikan media pembelajaran yang menyokong media pembelajaran cadaver.

\section{UCAPAN TERIMA KASIH}

Penulis mengucapkan terimakasih kepada seluruh mahasiswa kedokteran tahun 2019 yang telah menjadi subjek penelitian.

\section{DAFTAR PUSTAKA}

1. Munawaroh S (2015). Penggunaan 4C/ID dan active learning dalam pembelajaran anatomi dalam large group. Jurnal Pendidikan Kedokteran Indonesia 4(1):7-14

2. Azer SA \& Eizenberg N (2007). Do we need dissection in an integrated problembased learning medical course? Perceptions of first- and second-year students. Surgical and Radiologic Anatomy 29(2):173-180. doi:10.1007/s00276-007-0180-x.

3. Berrios Barillas, R. (2019). The Effect of 3D Human Anatomy Software on Online Students' Academic Performance. Journal of Occupational Therapy Education, 3 (2). doi.org/10.26681/jote.2019.030202

4. McLachlan JC \& Regan De Bere S (2004). How we teach anatomy without cadavers. The Clinical Teacher 1(2):49-52.

5. McMenamin PG, Quayle MR, McHenry CR, \& Adams JW (2014). The production of anatomical teaching resources using three-dimensional (3D) printing technology. Anatomical Sciences Education, 7(6):479-486. doi:10.1002/ase.1475.

6. Trelease RB (2002). Anatomical informatics: Millennial perspectives on a newer frontier. The Anatomical Record 269(5):224-235. doi:10.1002/ar.10177.

7. Pani JR, Chariker JH, Naaz F, Mattingly W, Roberts J, \& Sephton SE (2014). Learning with interactive computer graphics in the undergraduateneuroscience classroom. Adv Health Sciences Education 19(4), 507-528. doi:10.1007/s10459-013-9483-3. 
8. Tam MDBS, Hart AR, Williams SM, Holland R, Heylings D, \& Leinster S (2010). Evaluation of a computer program ("disect") to consolidate anatomy knowledge: A randomised-controlled trial. Medical Teacher 32(3):138-142. doi:10.3109/01421590903144110.

9. Losco CD, Grant WD, Armson A, Meyer AJ, \& Walker BF (2017). Effective methods of teaching and learning in anatomy as a basic science: A BEME systematic review: BEME guide no. 44. Medical Teacher 39(3):234-243. doi:10.1080/0142159x.2016.1271944

10. Peterson, D. C., \& Mlynarczyk, G. S. (2016). Analysis of traditional versus three- dimensional augmented curriculum on anatomical learning outcome measures. Anatomical Sciences Education 9(6):529-536._doi.org/10.1002/ase.1612

11. Yammine, K., \& Violato, C. (2015). A meta-analysis of the educational effectiveness of threedimensional visualization technologies in teaching anatomy. Anatomical Sciences Education 8(6):525-538. doi.org/10.1002/ase. 1510 